(2) Open Access Full Text Article

ORIGINAL RESEARCH

\title{
Anterior Segment Optical Coherence Tomography of Tear Film and Cornea in Systemic Lupus Erythematosus Patients
}

\author{
Mohamed Salah El-Din Mahmoud \\ Mohamed A Hamid iD \\ Mohamed Farouk Abdelkader (D) \\ Department of Ophthalmology, Faculty of \\ Medicine, Minia University, Minia, Egypt
}

Correspondence: Mohamed A Hamid Department of Ophthalmology, Faculty of Medicine, Minia University, Minia, Egypt Email drmohamedhamid83@mu.edu.eg
Purpose: To study tear film and corneal thickness measurements in systemic lupus erythematosus (SLE) patients compared to age-matched controls using anterior segment optical coherence tomography (AS-OCT).

Methods: This was a cross-sectional study. Study participants were divided into 3 groups: Group A: SLE patients with clinical dry eye, Group B: SLE patients without clinical dry eye and Group C: healthy controls. The lower tear meniscus parameters measured using AS-OCT were tear meniscus height (TMH), tear meniscus depth (TMD) and tear meniscus area (TMA). The central corneal and corneal epithelial thickness were automatically calculated. Results: The study included 40 eyes in Group A, 60 in Group B, and 100 in Group C. Mean

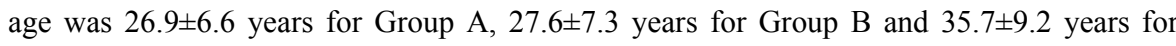
Group C $(\mathrm{p}=0.06)$. All subjects were females except for 1 male patient in Group A. Mean TMH, TMA and TMD in Group C were $487.7 \pm 185.6 \mu \mathrm{m}, 0.068 \pm 0.040 \mathrm{~mm}^{2}$, and $341.2 \pm 99.1$ $\mu \mathrm{m}$, respectively, which was significantly higher compared to Group A $(225.5 \pm 27.9 \mu \mathrm{m}$, $0.018 \pm 0.004 \mathrm{~mm}^{2}$ and $171.9 \pm 26.0 \mu \mathrm{m}$, respectively, all $\left.\mathrm{p}<0.001\right)$ and Group B (395.4 $\pm 118.8 \mu \mathrm{m}, \mathrm{p}<0.001 ; 0.05 \pm 0.04 \mathrm{~mm}^{2}, \mathrm{p}=0.016$ and $280.6 \pm 93.4 \mu \mathrm{m}, \mathrm{p}<0.001$, respectively). Group B eyes also had significantly higher parameters compared to Group A (all p < 0.001 ). Mean corneal and epithelial thickness in Group $C$ were $501.6 \pm 37.5 \mu \mathrm{m}$ and $53.3 \pm 4.5$ $\mu \mathrm{m}$, respectively, which was significantly higher compared to Group A $(496.1 \pm 24.1 \mu \mathrm{m}$, $\mathrm{p}=0.044$ and $49.5 \pm 3.5 \mu \mathrm{m}, \mathrm{p}<0.001$, respectively $)$ and Group B $(504.2 \pm 22.03 \mu \mathrm{m}, \mathrm{p}=0.046$ and $47.5 \pm 5.6 \mu \mathrm{m}, \mathrm{p}<0.001$, respectively). Group B eyes also had a significantly higher corneal thickness $(p=0.031)$ and epithelial thickness $(p=0.011)$ compared to Group A.

Conclusion: We demonstrated significant reduction of tear meniscus dimensions, central corneal thickness and epithelial thickness in SLE patients compared to age-matched controls using AS-OCT.

Keywords: anterior segment optical coherence tomography, tear film, dry eye disease, systemic lupus erythematosus

\section{Introduction}

Systemic lupus erythematosus (SLE) is a relapsing and remitting autoimmune connective tissue disorder that affects multiple organs including the skin, joints, kidneys, eye and brain. ${ }^{1}$ The global prevalence of the disease is estimated to range from 0.3 to 23.2 cases per 100,000 , and women are more likely to be affected than men., ${ }^{2,3}$

Ocular manifestations occur in about one third of SLE patients with keratoconjunctivitis sicca being the most common and characterized by tear film aqueous layer deficiency. Scleritis, retinal vasculitis and papillitis are considered the most 
serious ocular manifestations. ${ }^{4}$ The corneal epithelium is affected in SLE patients in the form of superficial punctate keratitis (SPK) which is believed to be caused by Sjögren's syndrome (SS). Some cases of non-infiltrative and infiltrative peripheral ulcerative keratitis (PUK) have also been identified. ${ }^{5}$

Schirmer's and fluorescein tear breakup time (TBUT) tests are two commonly used clinical methods to assess the tear film. ${ }^{6,7}$ The advent of anterior segment optical coherence tomography (AS-OCT) has provided a new noninvasive tool to image the tear film, measure the lower tear film height and area, total corneal thickness (pachymetry) and corneal epithelial thickness. ${ }^{8,9}$

The purpose of this study was to compare tear film parameters, corneal pachymetry and epithelial thickness maps between eyes of SLE patients and healthy eyes of age-matched controls.

\section{Patients and Methods}

\section{Ethical Considerations}

This was a cross-sectional observational study conducted at the Department of Ophthalmology, Minia University, Minia, Egypt, during the period from July 2020 to February 2021. The study was approved by the Institutional Review Board of the Faculty of Medicine, Minia University and adhered to the tenets of the Declaration of Helsinki. The study is registered on clinicaltrials.gov (NCT04873739). Written consent was obtained from each study participant prior to study enrollment after a thorough explanation of the nature of the study.

\section{Study Population}

SLE study participants were recruited from patients referred from the Department of Rheumatology, Minia University to our outpatient clinic for routine ocular examination. We included in our SLE arm all patients 18 years of age or older who had a confirmed diagnosis of SLE, according to the American College of Rheumatology (ACR) criteria. ${ }^{3}$ In the control group, we included ageand gender-matched healthy individuals who came to the outpatient clinic for routine checkup. Both eyes were included for each study participant.

Exclusion criteria were a diagnosis of secondary Sjogren's syndrome according to the ACR/European League against rheumatism criteria, ${ }^{10}$ the presence of any anterior segment abnormality, glaucoma, uveitis, history of intraocular or corneal refractive surgery, history of ocular trauma, habitual contact lens use, a spherical equivalent $>4$ $\mathrm{D}$, chronic use of topical medications or the presence of any systemic disease other than SLE. Subjects were excluded from the control group if they had evidence of dry eye on TBUT or Schirmer testing.

\section{Ophthalmologic Examination}

All study participants underwent a comprehensive ophthalmologic evaluation including history taking, automated refraction, measurement of uncorrected and best-corrected Snellen visual acuity, slit-lamp examination, intraocular pressure measurement and fundus examination.

A clinical diagnosis of dry eye disease was made based on the results of TBUT and Schirmer's test with topical anesthesia (STA). In TBUT, an impregnated fluorescein strip moistened with saline was inserted into the inferior conjunctival fornix and the patient was asked to blink once and then keep his/her eyes open. We measured the time interval between the last blink and the appearance of a dark spot in the precorneal tear film as observed using the blue filter of the slit-lamp under low magnification. The test was carried out twice and the results averaged. A break-up time of less than 10 seconds was considered abnormal. A single experienced clinician performed the test for all subjects (MSM). STA was performed after instillation of one drop of benoxinate hydrochloride $0.4 \%$ by inserting the test paper strip into the inferior fornix at the junction between the middle and lateral portions of the lower eyelid. After 5 minutes, the paper strip was removed, and the wet portion measured. A measurement of less than $15 \mathrm{~mm}$ was considered abnormal. According to the results of both tests, SLE patients were divided into 2 groups, the dry eye group and non-dry eye group. All eyes in the control group had no dry eye.

\section{AS-OCT Imaging}

Anterior segment imaging was done using the Avanti RTVue-XR platform (Optovue, Fremont, CA, USA) spectral domain OCT with the add-on lens of the corneal adaptor module (CAM-L mode: S/N 43386). Study participants were instructed not to use any topical medications 2 hours prior to imaging. Imaging was done between 11 $\mathrm{AM}$ and $1 \mathrm{PM}$ for all subjects to avoid confounding diurnal variation of measurements. The imaging room temperature was kept at $23-25{ }^{\circ} \mathrm{C}$ with a relative humidity of $40-45 \%$. The lower tear meniscus was detected using a horizontal line on the lower lid margin and a vertical one 
on the inferior cornea at the 6 o'clock position. Multiple images were captured until a good quality scan was obtained with good visibility of the concave profile of the tear meniscus from the inferior lid margin to the corneal/conjunctival surface. A single experienced operator performed AS-OCT imaging and manual measurements of tear meniscus parameters for all subjects (MFA). OCT measurements obtained from the lower tear meniscus included:

- Tear Meniscus Height (TMH): was manually measured using the Measure tool by joining the points corresponding to the upper corneo-meniscus junction to the lower eyelid-meniscus junction and expressed in $\mu \mathrm{m}$.

- Tear Meniscus Depth (TMD): was defined as the distance between the center of the upper boundary of the tear meniscus and the point at the bottom boundary where the cornea meets the eyelid and expressed in $\mu \mathrm{m}$.

- Tear Meniscus Area (TMA): was defined as the triangular area bounded superiorly by the tear meniscus surface, antero-inferiorly by the lid margin, and posteroinferiorly by the anterior surface of cornea and expressed in $\mathrm{mm}^{2}$.

\section{Corneal Pachymetry and Epithelial Thickness Maps}

A computer algorithm automatically maps the total corneal thickness (Pachymetry Map) and the corneal epithelial thickness (Epithelial Map) across the central $6 \mathrm{~mm}$ of the corneal surface. Each map is divided into 17 sectors. Only the central zone was used in our study.

\section{Statistical Analyses}

All statistical analyses were done using IBM SPSS Statistics for Windows, Version 25.0 (IBM Corp., Armonk, NY, USA). Snellen visual acuity measurements were converted into LogMAR for statistical analyses. Mean \pm standard deviation (range) was used to describe parametric quantitative data, while number (percentage) was used to describe categorical data. Parametric quantitative data were compared between the two groups using ANOVA test and post-hoc correction with Tukey's test, while qualitative data were compared using the Chi-Square test. Statistical significance was accepted at $\mathrm{p}<0.05$.

\section{Results \\ Demographic Data}

We included 100 eyes of 50 SLE patients in the study, 40 eyes of which were clinically diagnosed as having dry eye disease (Group A) and 60 eyes with no clinical evidence of dry eye (Group B). Table 1 summarizes Schirmer's and TBUT test values for each lupus group. The mean duration of the disease was 5.3 \pm 2.6 years in Group A and 5.1 \pm 2.9 years in Group B patients $(p=0.12)$. All study patients were on hydroxychloroquine as a standalone therapy. The daily dose of the drug did not exceed $6.5 \mathrm{mg} / \mathrm{kg}$ for any patient. We also included 100 eyes of 50 healthy controls in the study (Group C). Mean age was 26.9 \pm 6.6 years (range: 19-50 years) for Group A, 27.6 \pm 7.3 years (range: 19-50 years) for Group B and 35.7 \pm 9.2 years (range: 23-49 years) for Group C. All groups were balanced regarding age $(p=0.06)$. All study participants were females except for 1 male patient in Group A. Demographic data are summarized in Table 2.

\section{Tear Film Parameters}

All tear film parameters were significantly reduced in Group A and B compared to Group C. In control Group $\mathrm{C}$, mean TMH, TMA and TMD were 487.7 $\pm 185.6 \mu \mathrm{m}$, $0.068 \pm 0.040 \mathrm{~mm}^{2}$, and $341.2 \pm 99.1 \mu \mathrm{m}$, respectively. These values were significantly higher compared to Group A $\left(225.5 \pm 27.9 \mu \mathrm{m}, 0.018 \pm 0.004 \mathrm{~mm}^{2}\right.$ and 171.9 $\pm 26.0 \mu \mathrm{m}$, respectively, all $\mathrm{p}<0.001)$ as well as compared to Group B $\left(395.4 \pm 118.8 \mu \mathrm{m}, \mathrm{p}<0.001 ; 0.05 \pm 0.04 \mathrm{~mm}^{2}\right.$, $\mathrm{p}=0.016$ and $280.6 \pm 93.4 \mu \mathrm{m}, \mathrm{p}<0.001$, respectively). Group A eyes also had significantly decreased parameters when compared to Group B eyes (all p < 0.001).

\section{Corneal and Epithelial Thickness}

In control Group C, mean corneal and epithelial thickness were $501.6 \pm 37.5 \mu \mathrm{m}$ and $53.3 \pm 4.5 \mu \mathrm{m}$, respectively. These values were significantly higher compared to Group A (496.1 $\pm 24.1 \mu \mathrm{m}, \mathrm{p}=0.044$ and $49.5 \pm 3.5 \mu \mathrm{m}, \mathrm{p}<0.001$,

Table I Schirmer's and Fluorescein Tear Breakup Time (TBUT) Test Results for Lupus Patients

\begin{tabular}{|l|c|c|}
\hline Test & Group A* N=40 & Group B* N=60 \\
\hline Schirmer's (mm) & $9.3 \pm 2.8$ & $18.5 \pm 8.6$ \\
TBUT $(\mathrm{sec})^{\dagger}$ & $5.7 \pm 1.4$ & $1 \mathrm{I} .6 \pm \mathrm{I} .2$ \\
\hline
\end{tabular}

Notes: Data are expressed as mean \pm standard deviation. *Group A: SLE patients with clinical signs of dry eye; Group B: SLE patients with no clinical signs of dry eye. Abbreviation: ${ }^{\dagger} \mathrm{TBUT}$, tear breakup time test. 
Table 2 Demographic Data of All Study Groups

\begin{tabular}{|c|c|c|c|c|c|c|c|}
\hline & \multirow[t]{2}{*}{ Group $A * N=40$} & \multirow[t]{2}{*}{ Group $B * N=60$} & \multirow[t]{2}{*}{ Group $\mathbf{C} * \mathbf{N}=100$} & \multicolumn{4}{|c|}{$P$ value } \\
\hline & & & & All & A vs $B$ & A vs $C$ & B vs C \\
\hline Age (yrs) Mean $\pm S D$ (Range) & $26.9 \pm 6.6(19-50)$ & $27.6 \pm 7.3(19-50)$ & $35.7 \pm 9.2(23-49)$ & 0.062 & 0.891 & 0.071 & 0.90 \\
\hline \multicolumn{8}{|l|}{ Sex No. (\%) } \\
\hline Females & 19 (95\%) & $30(100 \%)$ & $50(100 \%)$ & 0.982 & 0.899 & 0.896 & 1.000 \\
\hline Males & I (5\%) & $0(0 \%)$ & $0(0 \%)$ & & & & \\
\hline
\end{tabular}

Notes: *Group A: SLE patients with clinical signs of dry eye; Group B: SLE patients with no clinical signs of dry eye; Group C: healthy control subjects.

respectively) as well as compared to Group B (504.2 $\pm 22.03 \mu \mathrm{m}, \mathrm{p}=0.046$ and $47.5 \pm 5.6 \mu \mathrm{m}, \mathrm{p}<0.001$, respectively). Group A eyes also had a significantly decreased corneal thickness $(p=0.031)$ and epithelial thickness $(p=0.011)$ compared to Group B eyes. Table 3 summarizes the comparison between the 3 groups regarding all ASOCT parameters.

Figures 1-3 demonstrate AS-OCT parameters in example patients from each study group. Figure 4 depicts scan positions as shown in infrared images of AS-OCT.

\section{Discussion}

Up to one third of SLE patients can develop ocular involvement. SLE may affect ocular adnexa, eye and/or optic nerve. The ocular manifestations usually mirror the systemic disease activity and can sometimes precede systemic symptoms. ${ }^{11}$ While the most visually devastating sequelae are retinal/optic nerve involvement, aqueous-deficient dry eye (ADDE) disease is the most common ocular manifestation, with a reported prevalence of $28-36 \%$ among SLE patients. ${ }^{12,13}$ Diminished aqueous tear film production is thought to be the result of chronic inflammation with immune complex deposition, inflammatory cell recruitment and the consequent production of proinflammatory mediators. $^{14}$
The central thickness of the tear film is about 4-6 $\mu \mathrm{m}$, which makes it difficult to visualize and quantify. Several tests are used in clinical practice as surrogates for tear film integrity, such as Schirmer test and TBUT. However, these tests are invasive and have limited reproducibility. ${ }^{15}$ Since its introduction in 1991, OCT has rapidly evolved to become the cornerstone of retina and optic nerve head imaging. ${ }^{16}$ AS-OCT has been widely used for detailed assessment of the different anterior segment structures, such as the conjunctiva, cornea and iridocorneal angle in both health and disease. It offers a non-invasive highresolution imaging modality that can accurately quantify the tear film. ${ }^{17}$

The lower tear film meniscus, which is a wedge-shaped layer found between the inferior lid margin and the surface of the bulbar conjunctiva or cornea, is usually analyzed to avoid artifacts from upper lid lashes and because its dimensions were found to be more specific and sensitive than the upper meniscus parameters. ${ }^{18}$ The 3 parameters derived from AS-OCT imaging of lower tear meniscus are TMH, TMD and TMA. These parameters have been validated and found to be reliable with high specificity and sensitivity. ${ }^{19}$ Furthermore, they have been shown to positively correlate to clinical tests, such as Schirmer test and TBUT. $^{20,21}$

Table 3 Comparison Between Study Groups Regarding All Measured as-OCT Parameters

\begin{tabular}{|c|c|c|c|c|c|c|c|}
\hline & \multirow[t]{2}{*}{ Group A* } & \multirow[t]{2}{*}{ Group B* } & \multirow[t]{2}{*}{ Group C* } & \multicolumn{4}{|c|}{$P$ value } \\
\hline & & & & All & $A$ vs $B$ & A vs $C$ & B vs C \\
\hline $\mathrm{TMH}(\mu \mathrm{m})$ & $225.5 \pm 27.9$ & $395.4 \pm 118.8$ & $487.7 \pm 185.6$ & $<0.001$ & $<0.001$ & $<0.001$ & $<0.001$ \\
\hline TMA $\left(\mathrm{mm}^{2}\right)$ & $0.018 \pm 0.004$ & $0.05 \pm 0.04$ & $0.068 \pm 0.040$ & $<0.001$ & $<0.001$ & $<0.001$ & 0.016 \\
\hline TMD $(\mu \mathrm{m})$ & $171.9 \pm 26.0$ & $280.6 \pm 93.4$ & $341.2 \pm 99.1$ & $<0.001$ & $<0.001$ & $<0.001$ & $<0.001$ \\
\hline Corneal Thickness $(\mu \mathrm{m})$ & $496.1 \pm 24.1$ & $504.2 \pm 22.0$ & $501.6 \pm 37.5$ & 0.042 & 0.031 & 0.044 & 0.046 \\
\hline Epithelial Thickness $(\mu \mathrm{m})$ & $47.5 \pm 5.6$ & $49.5 \pm 3.5$ & $53.3 \pm 4.5$ & $<0.001$ & 0.011 & $<0.001$ & $<0.001$ \\
\hline
\end{tabular}

Notes: *Group A: SLE patients with clinical signs of dry eye; Group B: SLE patients with no clinical signs of dry eye; Group C: healthy control subjects. 

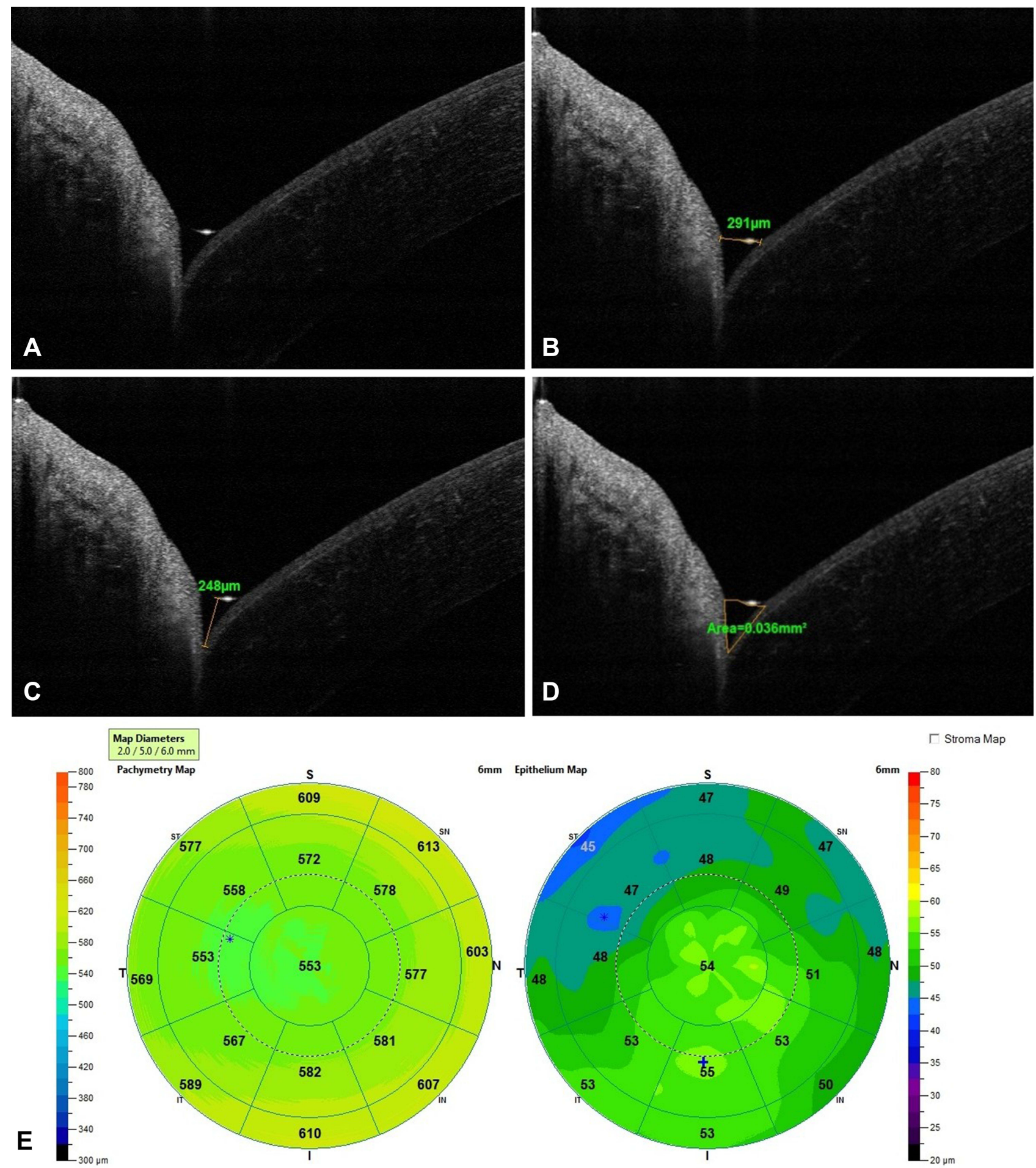

Figure I AS-OCT images of the right eye of a Group A patient; (A) lower tear meniscus (TM); (B) tear meniscus height (TMH) in $\mu$ m; $(\mathbf{C})$ tear meniscus depth (TMD) in $\mu \mathrm{m}$; (D) tear meniscus area (TMA) in $\mathrm{mm}^{2}$; (E) Pachymetry Map (Left) and Epithelial Map (Right).

We found significantly diminished OCT-measured tear meniscus parameters in SLE patients compared to controls. The difference was significant even in SLE patients with normal results in clinical testing, albeit to a lesser extent compared to SLE patients with clinical dry eye.
These findings are in agreement with previous studies that investigated dry eye in SLE patients using different techniques. ${ }^{11,21-23}$ All of our SLE study patients were on hydroxychloroquine standalone therapy, which is not known to affect tear film production or dry eye 

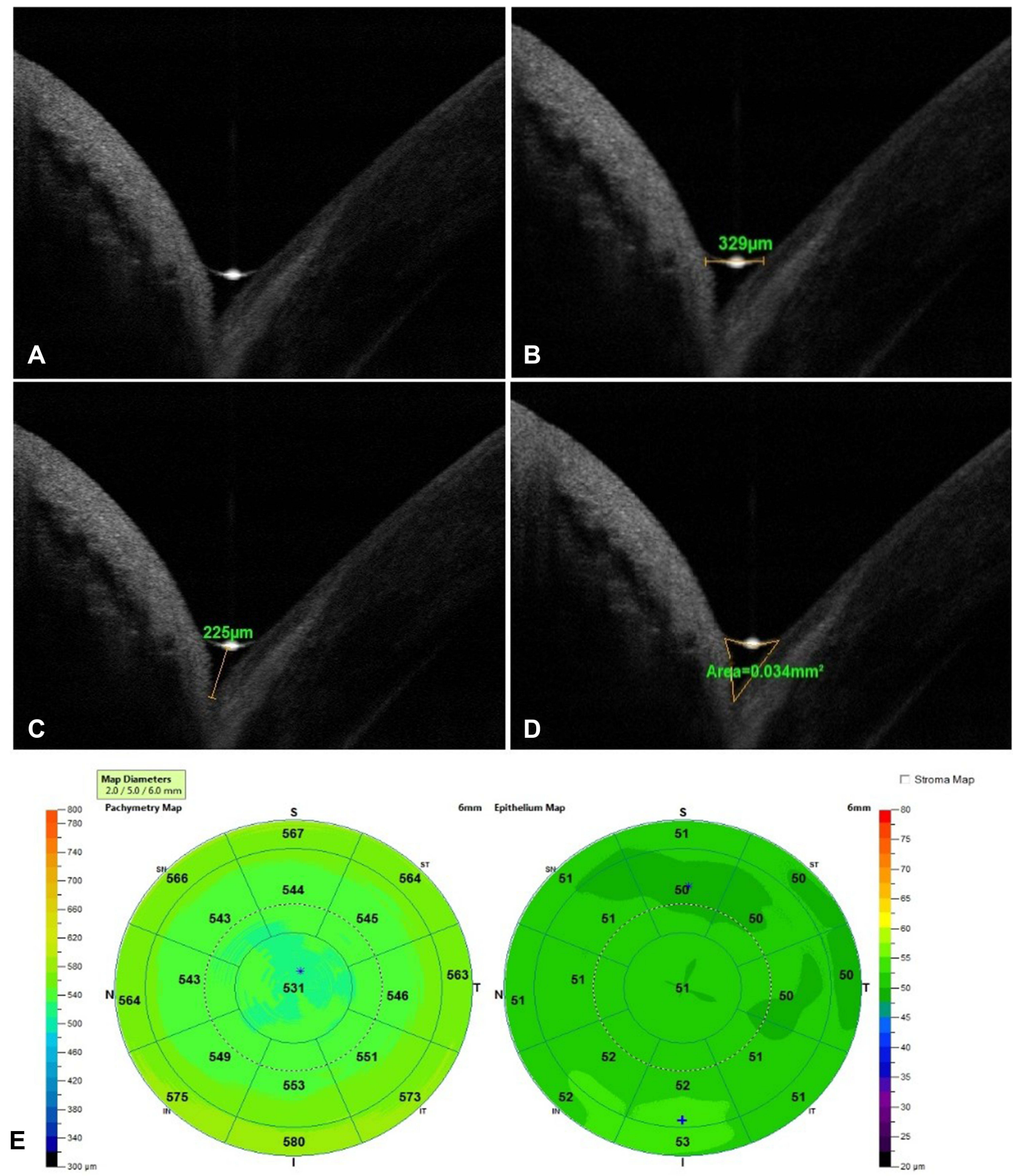

Figure 2 AS-OCT images of the left eye of a Group B patient; (A) lower tear meniscus (TM); (B) tear meniscus height (TMH) in $\mu \mathrm{m}$; (C) tear meniscus depth (TMD) in $\mu \mathrm{m}$; (D) tear meniscus area (TMA) in $\mathrm{mm}^{2}$; (E) Pachymetry Map (Left) and Epithelial Map (Right).

manifestations, so SLE treatment could not have confounded our results. ${ }^{24}$

To the best of our knowledge, this is the first study that uses AS-OCT for assessment of tear meniscus parameters in SLE patients. Previous studies utilized AS-OCT for dry eye evaluation in different settings. ${ }^{15,17}$ Most studies investigating dry eye in SLE patients relied on clinical tests, with few exceptions. Wang et al used a 

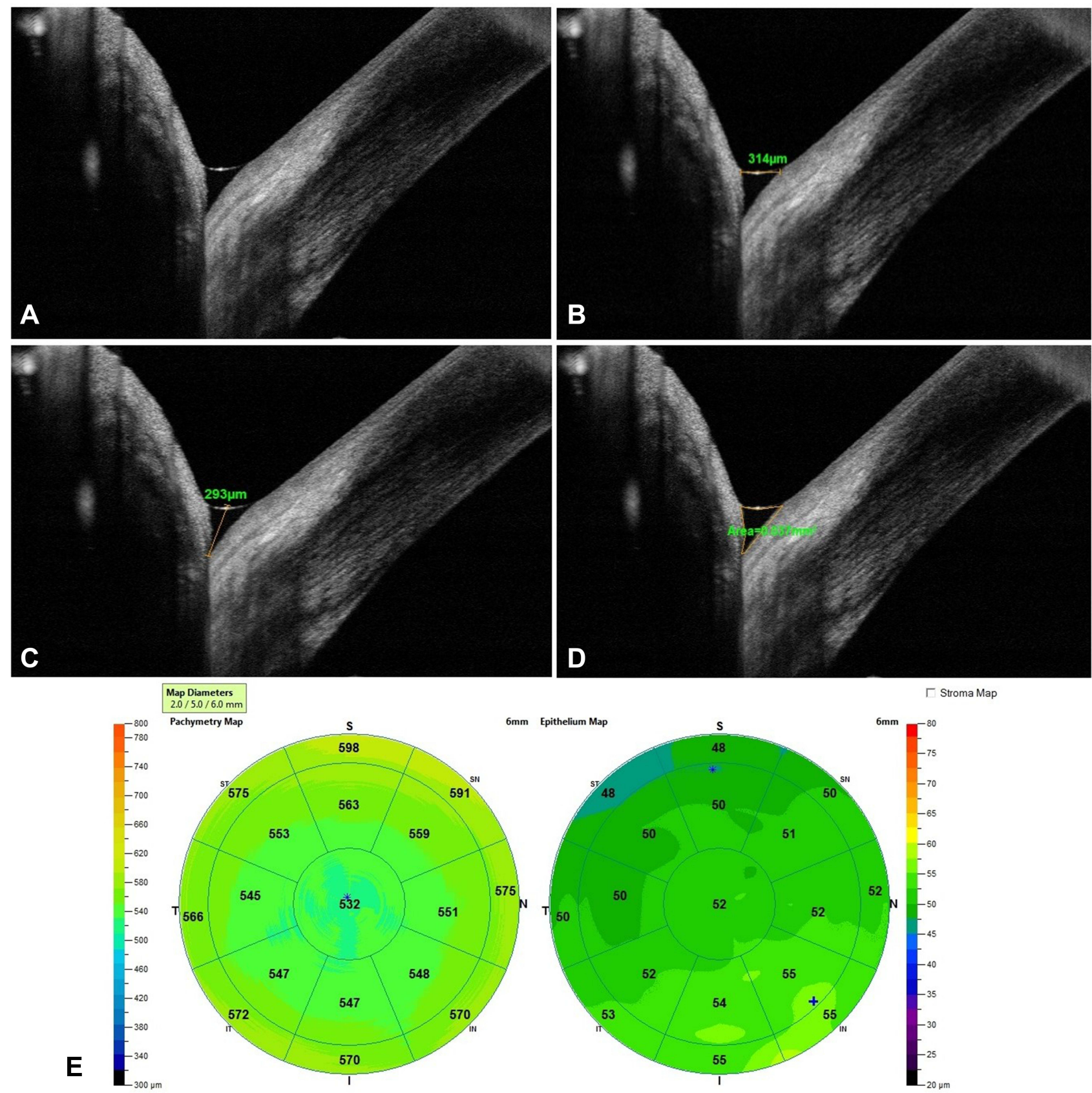

Figure 3 AS-OCT images of the right eye of a Group C patient; (A) lower tear meniscus (TM); (B) tear meniscus height (TMH) in $\mu$ m; (C) tear meniscus depth (TMD) in $\mu \mathrm{m}$; (D) tear meniscus area (TMA) in $\mathrm{mm}^{2}$; (E) Pachymetry Map (Left) and Epithelial Map (Right).

Scheimpflug-based imaging modality to demonstrate dry eye in one fourth of SLE patients without secondary Sjogren's syndrome. Moreover, they showed that the dry eye severity correlated with SLE activity. ${ }^{22}$ Corneal confocal microscopy was utilized by Resch and associated to image Langerhans Cells (LCs) density and morphology in the corneas of SLE patients. They relied on traditional clinical tests for dry eye assessment, including lid-parallel conjunctival folds, Schirmer test and TBUT. They found significant dry eye changes as well as increased central density and altered morphology of LCs in SLE patients compared to healthy controls. ${ }^{23}$

We also found that corneas of the SLE cohort had significantly less central corneal and epithelial thickness compared to healthy subjects. A previous study by Eissa et al utilizing dual Scheimpflug imaging found significantly lower pachymetry values in SLE corneas both at the corneal center and thinnest location. They postulated 

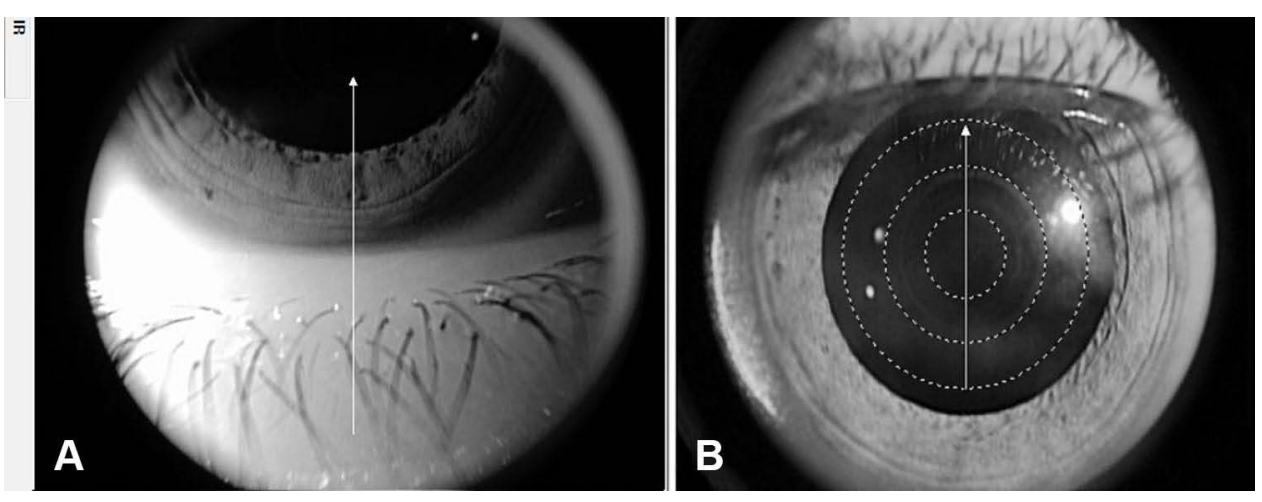

Figure 4 Infrared images showing AS-OCT scan positions; (A) vertical line scan at the 6 o'clock position of the lower lid-corneal junction to detect the lower tear meniscus (TM) in the right eye of a group A patient; (B) scan positions to measure corneal total and epithelial thickness in the central $6 \mathrm{~mm} z o n e$ in the left eye of a group B patient.

that the corneal stroma, being primarily made of type 1 collagen, was affected by the connective tissue abnormalities that are the hallmark of SLE. ${ }^{25}$ Unlike Scheimpflug imaging, AS-OCT allows for the measurement of corneal epithelial thickness. We hypothesize that the decreased epithelial thickness we observed in SLE patients compared to controls, and also in SLE patients with dry eye compared to those without clinically detectable dry eye, is a result of decreased tear production and the subsequent dehydration and devitalization of the corneal epithelium.

Limitations of our study include the relatively recent onset of disease in SLE patients and the lack of longitudinal follow-up. It would be valuable if tear film changes in SLE patients could be studied over an extended period as the disease has a waxing and waning nature and ocular dryness could follow the same course. The strengths include the large number of patients and the use of AS-OCT to accurately quantify the lower tear meniscus and corneal thickness.

\section{Conclusions}

In conclusion, using AS-OCT we found SLE patients to have reduced tear meniscus dimensions, as well as decreased central corneal and corneal epithelial thickness compared to healthy controls. More importantly, we found that SLE patients with no clinical signs of dry eye had diminished tear meniscus parameters compared to healthy subjects. These preclinical findings would be missed without the use of AS-OCT, which highlights its importance in the early detection of dry eye signs in this subset of patients, allowing for early treatment and also accurate quantitative follow-up during the course of treatment. Among the different newer imaging tools for tear film assessment, ${ }^{26}$ AS-OCT might be the most cost efficient, as it only requires an add-on attachment to the OCT machine widely available in many ophthalmology practices around the world.

\section{Data Sharing Statement}

The authors will share individual deidentified participant data upon request via the corresponding author's email (drmohamedhamid83@mu.edu.eg) including raw data spread on an Excel sheet and AS-OCT images. The data will be available to share for a year after the publication date.

\section{Disclosure}

The authors declare that they have no conflicts of interest for this work.

\section{References}

1. Palejwala NV, Walia HS, Yeh S. Ocular manifestations of systemic lupus erythematosus: a review of the literature. Autoimmune Dis. 2012;2012:290898. doi:10.1155/2012/290898

2. Rees F, Doherty M, Grainge MJ, Lanyon P, Zhang W. The worldwide incidence and prevalence of systemic lupus erythematosus: a systematic review of epidemiological studies. Rheumatology (Oxford, England). 2017;56(11):1945-1961. doi:10.1093/rheumatology/kex260

3. Yu C, Gershwin ME, Chang C. Diagnostic criteria for systemic lupus erythematosus: a critical review. J Autoimmun. 2014;48-49:10-13. doi:10.1016/j.jaut.2014.01.004

4. Read RW, Stegmann H, Aranha Dos Santos V. Clinical mini-review: systemic lupus erythematosus and the eye. Ocul Immunol Inflamm. 2004;12(2):87-99. doi:10.1080/09273940490895308

5. Gomes BA, Santhiago MR, Jorge PA, Kara-José N, Moraes HV, KaraJunior N. Corneal involvement in systemic inflammatory diseases. Eye Contact Lens. 2015;41(3):141-144. doi:10.1097/ICL.0000000000000141

6. Benítez Del Castillo JM, Wasfy MA, Fernandez C, Garcia-Sanchez J. An in vivo confocal masked study on corneal epithelium and subbasal nerves in patients with dry eye. Invest Ophthalmol Vis Sci. 2004;45 (9):3030-3035. doi:10.1167/iovs.04-0251

7. Kanellopoulos AJ, Aslanides IM, Asimellis G. Correlation between epithelial thickness in normal corneas, untreated ectatic corneas, and ectatic corneas previously treated with CXL; is overall epithelial thickness a very early ectasia prognostic factor? Clin Ophthalmol (Auckland, NZ). 2012;6:789-800. doi:10.2147/OPTH.S31524 
8. Nguyen P, Huang D, Li Y, et al. Correlation between optical coherence tomography-derived assessments of lower tear meniscus parameters and clinical features of dry eye disease. Cornea. 2012;31 (6):680-685. doi:10.1097/ICO.0b013e3182261577

9. Li Y, Tan O, Brass R, Weiss JL, Huang D. Corneal epithelial thickness mapping by Fourier-domain optical coherence tomography in normal and keratoconic eyes. Ophthalmology. 2012;119(12):24252433. doi:10.1016/j.ophtha.2012.06.023

10. Vitali C, Bombardieri S, Jonsson R, et al. Classification criteria for Sjögren's syndrome: a revised version of the European criteria proposed by the American-European Consensus Group. Ann Rheum Dis. 2002;61(6):554-558. doi:10.1136/ard.61.6.554

11. Silpa-archa S, Lee JJ, Foster CS. Ocular manifestations in systemic lupus erythematosus. $\mathrm{Br} J$ Ophthalmol. 2016;100(1):135-141. doi:10.1136/bjophthalmol-2015-306629

12. Wangkaew S, Kasitanon N, Sivasomboon C, Wichainun R, Sukitawut W, Louthrenoo W. Sicca symptoms in Thai patients with rheumatoid arthritis, systemic lupus erythematosus and scleroderma: a comparison with age-matched controls and correlation with disease variables. Asian Pacific J Allerg Immunol. 2006;24(4):213-221.

13. Gilboe IM, Kvien TK, Uhlig T, Husby G. Sicca symptoms and secondary Sjögren's syndrome in systemic lupus erythematosus: comparison with rheumatoid arthritis and correlation with disease variables. Ann Rheum Dis. 2001;60(12):1103-1109. doi:10.1136/ard.60.12.1103

14. Heiligenhaus A, Dutt JE, Foster CS. Histology and immunopathology of systemic lupus erythematosus affecting the conjunctiva. Eye (London, England). 1996;10(4):425-432. doi:10.1038/eye.1996.94

15. Stegmann H, Aranha Dos Santos V, Messner A, et al. Automatic assessment of tear film and tear meniscus parameters in healthy subjects using ultrahigh-resolution optical coherence tomography. Biomed Opt Express. 2019;10(6):2744-2756. doi:10.1364/BOE.10.002744

16. Fujimoto J, Swanson E. The development, commercialization, and impact of optical coherence tomography. Invest Ophthalmol Vis Sci. 2016;57(9):Oct1-oct13. doi:10.1167/iovs.16-19963
17. Gumus K, Pflugfelder SC. Anterior Segment Optical Coherence Tomography (AS-OCT) in the management of dry eye. Int Ophthalmol Clin. 2017;57(2):13-22. doi:10.1097/IIO.0000000000000164

18. Shen M, Li J, Wang J, et al. Upper and lower tear menisci in the diagnosis of dry eye. Invest Ophthalmol Vis Sci. 2009;50(6):27222726. doi:10.1167/iovs.08-2704

19. Czajkowski G, Kaluzny BJ, Laudencka A, Malukiewicz G, Kaluzny JJ. Tear meniscus measurement by spectral optical coherence tomography. Optomet Vision Sci. 2012;89(3):336-342. doi:10.1097/ OPX.0b013e318242042b

20. Ibrahim OM, Dogru M, Takano Y, et al. Application of visante optical coherence tomography tear meniscus height measurement in the diagnosis of dry eye disease. Ophthalmology. 2010;117 (10):1923-1929. doi:10.1016/j.ophtha.2010.01.057

21. Wang J, Palakuru JR, Aquavella JV. Correlations among upper and lower tear menisci, noninvasive tear break-up time, and the Schirmer test. Am J Ophthalmol. 2008;145(5):795-800. doi:10.1016/j.ajo.2007.12.035

22. Wang A, Gu Z, Liao R, Shuai Z. Dry eye indexes estimated by keratograph $5 \mathrm{M}$ of systemic lupus erythematosus patients without secondary Sjögren's syndrome correlate with lupus activity. $J$ Ophthalmol. 2019;2019:8509089. doi:10.1155/2019/8509089

23. Resch MD, Marsovszky L, Németh J, Bocskai M, Kovács L, Balog A. Dry eye and corneal Langerhans cells in systemic lupus erythematosus. $J$ Ophthalmol. 2015;2015:543835. doi:10.1155/2015/543835

24. Wang SQ, Zhang LW, Wei P, Hua H. Is hydroxychloroquine effective in treating primary Sjogren's syndrome: a systematic review and meta-analysis. BMC Musculoskelet Disord. 2017;18(1):186. doi:10.1186/s12891-017-1543-z

25. Eissa IM, Nassar GA, Arfeen SA, Dahab AA. Evaluation of central and peripheral corneal thicknesses in patients with systemic lupus erythematosus. Clin Ophthalmol (Auckland, NZ). 2020;14:589-595. doi:10.2147/OPTH.S234568

26. Wolffsohn JS, Arita R, Chalmers R, et al. TFOS DEWS II diagnostic methodology report. Ocul Surf. 2017;15(3):539-574.
Clinical Ophthalmology

\section{Publish your work in this journal}

Clinical Ophthalmology is an international, peer-reviewed journal covering all subspecialties within ophthalmology. Key topics include: Optometry; Visual science; Pharmacology and drug therapy in eye diseases; Basic Sciences; Primary and Secondary eye care; Patient Safety and Quality of Care Improvements. This journal is indexed on PubMed
Dovepress

Central and CAS, and is the official journal of The Society of Clinical Ophthalmology (SCO). The manuscript management system is completely online and includes a very quick and fair peer-review system, which is all easy to use. Visit http://www.dovepress.com/ testimonials.php to read real quotes from published authors. 